\title{
Postmodernism and Classical Chinese Philosophy
}

\author{
Yong-Kang Wei \\ University of Texas (RGV), Texas, USA
}

\begin{abstract}
While over two thousand years apart, Western postmodernism and ancient Chinese philosophy share some extraordinary similarities, especially epistemology wise. For example, they both recognize the role of language in constructing, and limiting, knowledge and reality. This is because thinkers of different cultures and geographical regions, and of different historical periods, can possibly come up with similar philosophical conclusions when addressing what is commonly known as the "human condition". The paper will discuss, in general terms, some of the philosophical similarities between postmodernism and classical Chinese philosophy; it will also take a close look at three concepts in Chinese philosophy that register strong affinity with Western postmodernism: namely, change, dialectic, and relativism.
\end{abstract}

Keywords: postmodernism, modernism, classical Chinese philosophy

\section{Introduction}

Postmodernism, as a philosophical concept, was first introduced in China by Fredric R. Jameson in 1985, when he was lecturing on "postmodernism" and "cultural theory" at Peking University (Wang, 2008). So readers may immediately sense a chronological incongruity between postmodernism and classical Chinese philosophy. However, it is quite possible, I would argue, that thinkers of different cultures and geographical regions, and of different historical periods, can come up with similar conclusions when addressing what is commonly known as the “human condition”. For example, Confucius’ “已所不欲, 勿施于人” (Don’t do things to others that you don't want done to yourself) is echoed, almost identically, in the Christian Bible, and Protagoras' (490-420 B.C.) paradox rings very similar to the “two-argument” theory (两可论) of Deng $\mathrm{Xi}^{1}$ (邓 析, 545-501 B.C.), a Chinese philosopher of the Spring and Autumn Period.

Back in 2013, when I met Professor Thomas Lutze, an American historian, at a conference in China, he immediately spoke of his interest in Zhuangzi (庄子), a prominent figure in classical Chinese philosophy, saying he felt strongly about Zhuangzi being a "postmodernist" because of a "relativistic" spirit in his worldview (personal communication, November 28, 2013). Lutze is by no means alone. Gier (2000), author of Spiritual Titanism: Indian, Chinese, and Western Perspectives, also names Zhuangzi, a postmodernist philosopher. Along with Confucius (孔子) and Xunzi (荀子). In his book, Gier reiterates a view held by other Western scholars that Zhuangzi is "the ancient Chinese equivalent of Jacques Derrida," because both of them share the postmodern traits of "skepticism, relativism, and extreme distrust of language" (p. 215). The story

\footnotetext{
Yong-Kang Wei, Ph.D., Associate Professor, Department of Writing and Language Studies, University of Texas (RGV).

Correspondence concerning this article should be addressed to the author of Dept. of WLS, UTRGV, Brownsville Campus, One West University Blvd., Brownsville, Texas, 78520, USA.

1 Deng Xi's statement that "yes can be seen as no and no as yes" is very similar to Protagoras' paradox: Every issue has two opposing logoi (arguments), both of which are feasible.
} 
about Zhuangzi suggests that the appreciation of postmodern philosophy should not be based entirely in Western settings around the 20th century—even by Western standards.

The purpose of this paper is to explore the connection between Western postmodernism and ancient Chinese thoughts. However, due to the enormity of the task, I will have to limit the paper to two sections: One is to discuss, in general terms, some of the philosophical similarities between the two; the other is to look closely at some of the key concepts in Chinese philosophy that register affinity with Western postmodernism. But, first, what is postmodernism?

\section{Philosophical Affinities}

Postmodernism is a slippery term, defying simple definitions. The general consensus is that it has grown out of modernism, but to the point of turning against the latter, especially epistemology wise. Encyclopaedia Britannica (2013) defines it as a late 20th century movement in Western philosophy "characterized by broad skepticism, subjectivism, or relativism; a general suspicion of reason; and an acute sensitivity to the role of ideology in asserting and maintaining political and economic power." Apparently, those characteristics_-“skepticism”, "subjectivism”, "relativism”, "suspicion of reason”, etc.—are nothing alien to early Chinese thought, if readers have read Laozi, Zhuangzi, and many other prominent thinkers of antiquity.

To return to the question on postmodernism, the major difference between modernism and postmodernism, in my view, lies in their approaches to knowledge and reality. Modernism takes a foundational approach, assuming that there is such a thing as absolute or universal, which is also accessible to individuals through the very means of reason. Postmodernism, on the other hand, takes a non-foundational approach, insisting that there is no such thing as absolute or independently existing. Even if the absolute does exist, a postmodernist would argue, it will be beyond us, simply because of the finite nature of human experience. To complicate the situation, there is no reliable way to speak about the world as it is, for the human subjectivity invariably participates in, and mingles with, our attempts to understand and describe the world. Hence, postmodernists are skeptical of any kinds of claim on Truth.

However, postmodernists do acknowledge and even accept "small" truths: That is, truths as local, situated in time and space, truths as entities socially and linguistically constructed, and, in short, truths as relative and non-foundational. The term "relative" suggests that truths as such are essentially contextualized, culturally, historically, politically, or economically, existing only in relation to something else rather than standing by itself-alone. This sort of relativist approach to truth is reminiscent of early Chinese philosophy (for example, of the yin-yang interactive model), which predominantly engages in correlative thinking, instead of analytical, to tackle the problematics of reality. Chinese correlative thinking, points out Graham (1992), among others, differs drastically from Western analytical thinking in that it stresses "complementary polarities" instead of "conflicting opposites (truth/falsehood, good/evil)," the latter typically seen in Western conceptual schemes (Unreason, p. 64).

Western thinking not only imposes directly contradictory oppositions, but also has the tendency to position one end of the polarity as independent of the other. The West, says Graham, "habitually treat[s] A as 'transcendent' in the sense that A is conceivable without B but not B without A; for Westerners there could be God without world, reality without appearance, good without evil” (p. 65). To the contrary, the Chinese scheme treats A and B as "interdependent with A only relatively superior, and the chain does not lead to 'good/evil'” (p. 64): A exists because of B, and yin exists because of yang, or vice versa. 
Correlative thinking, I would like to add, is much like relativistic thinking for the reason that under such thinking things are seen as relative to (the opposite) others, examples of which can be seen in the Zhuangzi among other Chinese classics: "When there is life, there is death, and when there is death, there is life. When there is possibility, there is impossibility, and when there is impossibility, there is possibility. Because there is right, there is wrong. Because there is wrong, there is right” (qi-wulun). ${ }^{2}$

Any student familiar with early Chinese thought could not help but notice the notion of ming-shi (名实), translated in English as "name and object" or "name and actuality". It embraces a correlative relationship, a "special bond that exists between names and actualities" (Makeham, 1994, p. 145): Names exist because there are actualities to be designated by them; on the other hand, actualities cannot exist, or at least in a meaningful way to the human mind, without proper names assigned to them. However, between names and actualities, observes Makeham, early Chinese philosophers, with a few exceptions, pay much more attention to the former because, for them, knowledge of the world, as the author explains, following Feng Youlan, "begins with knowledge of names" (p. 52). Actually we can see this very clearly by reading Lao Zi: "The name is the mother of ten thousand things" (Tao-Te Ching, ch.1). But what is significant here is the recognition in early Chinese thought of reality as a linguistic construction, of which Western postmodernists are keenly aware (Hicks, 2004, p. 6), albeit 2000 years later.

The idea of ming-shi tells of an attitude towards language quite different from that of the Greco-Roman tradition, which treats language as "an enterprise to represent or depict or describe an external reality independent of man and society” (Lenk, 1993, p. 6). In the Chinese tradition, however, language functions primarily as an epistemological system, which is to make distinctions of the world perceived to be filled with correlated entities (everything relates to everything else), as seen in the model of yin-yang duality, rather than to express the certainty about a transcendent truth as advocated by Plato and other Western thinkers. For a Westerner, language and reality can be separable, but to the Chinese, language and reality are one, in the sense that humans have to resort to language to make distinctions between yin and yang, good and bad, right and wrong, etc. In other words, the signifier is also the signified. ${ }^{3}$

This may explain why early Chinese thinkers are so obsessed with zheng-ming (正名), or rectification of names, as seen, for example, in the doctrines of Confucius and his follower Xunzi. Obviously, in their mind is the constructionist role of language in shaping and even creating reality of the world. However, a closer look at Confucius' statement on "correct naming”4 may reveal to the reader that the Great Master is also concerned about "the socio-political role that ming is perceived to play," understanding that language "can and should be used to prescribe shi” (Makeham, p. xv). Confucius' concern is apparently shared by the modern-day poststructuralists, who recognize language as "a principal site for the production of social realities and political conflict” (Seidman, 1994, p. 201). Inherent in language is its "regulative function” in shaping "people's attitudes and inclinations to act” (Hansen, 1983, p. 59); thus, Confucius' insistence on the rectification of names

\footnotetext{
${ }^{2}$ English translation quoted from A Short History of Chinese Philosophy by Feng Youlan. The original in Chinese: “方生方死, 方死方生. 方可方不可, 方不可方可. 因是因非, 因非因是” (齐物论).

${ }^{3}$ That the signifier is the signified is a noted proposition by postmodernists, like Derrida and Foucault, but it was already contained long ago in classical Chinese philosophy.

${ }^{4}$ The full statement: "If names are not rectified, speech is not appropriate. If speech is not appropriate, then affairs are not completed. If affairs are not completed, then ritual and music do not flourish. If ritual and music do not flourish, then punishments and penalties do not hit the mark. If punishments and penalties do not hit the mark, then the people have nothing to occupy their hands and feet”. (名不正则言不顺, 言不顺则事不成, 事不成则礼乐不兴, 礼乐不兴则刑罚不中, 刑罚不中则民无所措手足).
} 
can be seen as an effort to rectify people's moral conduct. A discerning reader may sense a denial of human agency in the statement about "correct naming", as the Great Master is devoting more of his attention to the "names" than to the humans for his li (礼) restoration project. Put differently, language weighs more in the Confucian moral system than the very person who speaks it. This is also an attitude held by poststructuralists who "underscore the role of language in forming individual subjectivity and social institutions" (Seidman, p. 201), so, Confucius, we might just say, is a "poststructuralist” in today's terms.

Again, we can see a close affinity between postmodernism and ancient Chinese thought when it comes to comprehending language and other related topics philosophically. This is especially true with Michel Foucault, who has written extensively on language, knowledge, reality, truth, power, etc. Noticeably, Foucault frequently uses the term "discourse" in his work, instead of "language", the reason being that the former means more for the author, way beyond its linguistic premises. As far as Foucault is concerned, discourse constitutes a social practice, "a form of action, and not a reflection of the world” (Bizzell \& Hertzberg, 1990, p. 1126). We can see this clearly in his Archaeology of Knowledge (1972), in which he argues that "to speak is to do something-something other than to express what one thinks" (p. 209). As such (i.e., as social practices, not just groups of signs), discourses "systematically form the objects of which they speak" (p. 49). Foucault's statementis reminiscent of the Daoist claim that language is "the mother of then thousand things" (Tao Te Ching 1).

That Foucault equals discourse with "a practice" is comparable to the notion of ming-shi in ancient Chinese philosophy, which recognizes the active role of language in constructing "actuality", as discussed earlier. And Foucault (1995) shows a sort of "Confucian" insight when he speaks of discourse as institutionalized practices of representation (i.e., naming) exercising its disciplinary or normative power over the speaking subjects with "an obscure set of anonymous rules" (Discipline, p. 210). The "discursive control", according to Foucault (1990), "binds individuals to certain types of enunciation and consequently forbids them all others" ("The Order of Discourse," pp. 1162-1163). Foucault exposes the "control” as a modern-day norm, but it was also a norm Confucius envisioned when proposing his "rectification of names". To rectify for Confucius is indeed to "discipline" for Foucault, that is, to normalize people's conduct into "their universally recognized behaviour" through enforcing conformity "to the same model [so that] they might all be like one another" (Discipline, pp. 181-182).

I wish my point is made here, namely, that classical Chinese philosophy is in many ways already "postmodern". In the next section, I would like to further discuss its philosophical "tie" with Western postmodernism by looking at some of the key concepts in its "repertoire".

\section{Key Concepts in Chinese Philosophy: A Closer Look}

To do a comprehensive discussion of relating early Chinese thought to postmodernism would be an impossible task for this paper, but we can at least take a close look at some of the key concepts in the system of Chinese philosophy to develop some sort of insight into its postmodern "leanings". This part of the paper will be dedicated to discussing three of such concepts: (1) change, (2) dialectic, and (3) relativism.

\section{The Concept of Change}

The first coming to mind is the notion of "change", which is elaborated at full length through the depictions of sixty-four sets of hexagrams in the Yi-Jing (the Book of Changes), believed to "[provide] access to 
the deepest access the 'Chinese mind' and [embody] the very essence of Chinese culture” (Schwartz, 1989, p. 390). The book describes change as the ultimate reality of the universe driven by constant interactions between two basic forces of opposites: yin and yang. The notion of change differentiates Chinese philosophy fundamentally from traditional Western philosophy, as the latter is driven by a seemingly never-ending search for a timeless essence of "being” supposedly underlying change or becoming, as seen typically in Plato's idealism.

Then, why the difference? I think Graham explains it well: Chinese thinking is correlative, "in terms of process rather than of static entities" (Unreason 77). Change is to process what essence is to a static entity, the latter pointing to a metaphysical force independent of myriads of changes: For example, the objective force of materiality in Marxism. But within the process (or correlative) mode of thinking, "there is no One behind the many; there are, rather, many ones” (Hall \& Ames, 1998, p. 40). The "One versus many” opposition also sets apart the movements of modernism and postmodernism in the West, with the former insisting on the absolute or the universal, assuming an all-encompassing essence as the foundation of knowledge and reality and the latter countering such a foundational approach, arguing instead for understanding knowledge and reality as socially constructed: Relative, situated, and, above all, subject to the laws of change. It would seem that Chinese thinking is already "postmodern", due to its correlative methods and its fixation on change.

Many may immediately point out the concept of the Dao (Way, also spelled as Tao) as a metaphysical force in early Chinese philosophy. For example, in Dao De Jing (also Tao-Te Ching), the "nameless" Dao is described as "the beginning of heaven and earth" (Tao-Te Ching, ch.1). Laozi also states: "The Tao begot one, one begot two, two begot three, and thee begot the ten thousand things" (ch.42). So, clearly, the Dao is the absolute, the essential One behind the many. However, classical Chinese philosophy, as many Western scholars have rightly observed, is very much a practical philosophy. Unlike their Greek counterparts, who were so possessed with rational demonstration in their quest for the absolute truth, supposedly independent of human experience, ancient Chinese thinkers (at least the vast majority of them) appeared to take a "let-it-go" attitude toward the absolute, so that they could redirect their energy to using what had already been accepted as true, like the Dao, to promote their moral or political agendas, as seen, for example, in Confucius' teachings. Graham (1989) sums it up well: for Confucius and Laozi, "problem-solving without useful purpose is a pointless frivolity” (Disputers, p. 7).

The Dao is considered beyond reach in early Chinese thought in that it cannot be "seen”, "heard," "held" or even "imagined" (Tao-Te Ching, ch.14) beside being "nameless". And if we compare it with the transcendental truth formulated in the Platonic fashion, we may see the immediate difference, for Plato believes that absolute truth, the One, can be accessible to humans if a rigorous reasoning, modeled after his dialectic, ${ }^{5}$ is in place. Western philosophy is known to have been driven by what Derrida (1976) calls "logocentrism” (p. 11) since Plato, phrased after the Greek term logos (i.e., logic, reason, language, etc.), but what is celebrated in the logocentric tradition is indeed Plato's idealistic notion that absolute truth can somehow be reached by humans. The ancient Chinese, on the other hand, were much more pragmatic: Instead of finding out what the Dao is, they basically left it alone and focused their attention on the vicissitudes of this mundane world; instead of generalizing about the universe using a metanarrative, they chose to deal with the problematics of "ten thousand things” (wanwu; 万物), or the particulars of an ever-changing universe. Needless to say, ancient

${ }^{5}$ Plato's dialectic is just another term for philosophy. 
Chinese pragmatism resonates deeply with the postmodern movement, which "abandons absolute standards, universal categories, and grand theories in favor of local, contextualized, and pragmatic conceptual strategies" (Seidman, p. 207).

\section{The Concept of Dialectic}

Dialectics (辩证) is another concept that takes a predominant spot in ancient Chinese philosophy. Twinned with the principle of change, the notion of dialectics in Chinese thought is typically formulated as a yin-yang dynamic where two opposites constantly compete with and complement one another, projecting both tension and harmony. For that reason, yin-yang can also be seen as a metaphor for “unity of opposites”.

But the yin-yang dialectic is also a paradox (悖论), where one opposite not only affirms but at the same time undermines the existence of the other, in the sense that if one does not exist, then the other does not either. Apparently, the earlier mentioned ming-shi is such a paradox. I would add that the notion of paradox is nothing new in Western thought, as seen, for example, in Protagoras' two-logoi statement. However, Chinese paradox is often characterized by an epistemological dilemma, where knowledge or knowing is affirmed through language, but at the same time undermined exactly because of such affirmation, as exemplified through Zhuangzi's "truth of no truth" (Loy, 1996, pp. 51-67).

The dilemma can also be described as a tradition of "speaking the unspeakable" in classical Chinese philosophy, as seen in the writings of Laozi and Zhuangzi, among others. For instance, despite his claim that the Dao is nameless and ineffable, Laozi still names it (as "the Dao") and keeps talking about it. In fact, the whole Da De Jing is centering on expositions of the Dao. Notably, Laozi is speaking of the unspeakable, the infinite, or the absolute by relying on "spinning" the speakable, the finite, and the relative-language. However, using the relative to speak of the absolute may prove just the opposite: Either the absolute does not exist, or it is just another relative. In other words, when affirmed, the absolute is undermined at the same time.

Derrida's deconstruction appears to operate in a similar manner. By demonstrating that the absolute is affirmed by the relative, truth affirmed by non-truth, and so on, Derrida is able to expose an epistemological paradox embedded in the relativistic nature of language: That is, the so-called metaphysical principles are just "part of a system, rather than the foundation for it". And they "are always defined by what they exclude, by their opposite" (Berkson, 1996, p. 106). Thus, reminiscent of Zhuangzi’s "truth of no truth", deconstruction manages to subvert an order of truth it aims to uncover through the very system of language.

Deconstruction's congruence with Chinese dialectics is more than obvious in that it also operates in a way to show that A exists because of B or vice versa, as formulated in the yin-yang model. As Berkson points out, "Deconstruction shows ... how each inheres within the other" (ibid). But the Western system of binary opposites, we may recall, tends to privilege one at the expense of the other, as if " $\mathrm{A}$ is conceivable without $\mathrm{B}$ but not B without A," to quote Graham again (Unreason, p. 65). Clearly, what is privileged in the end is the "law of noncontradiction" (Bergson, p. 106), grounded firmly in Western idealism of metaphysical principles. Derrida has a political agenda in his mind with his deconstruction: That is, to undermine the "dominant" A by exposing its interdependence with the "suppressed" B, typically marginalized as "the Other" in the Western system of binary opposites (Berkson, p. 107). Well, time will tell whether Derrida will succeed, but at least we can see that his deconstruction operates on a philosophical basis very similar to Chinese dialecticism.

\section{The Concept of Relativism}

Relativism seems to be the natural sequel of a discussion on Chinese dialectics. It is implied in and 
intertwined with dialecticism in early Chinese philosophy to such an extent that one can rarely separate the two from each other. For instance, in this statement from the Zhuangzi: "The sun at noon is the sun setting. The thing born is the thing dying (日方中方睨, 物方生方死)" (Zhuang Tzu 33; 庄子: 天下第三十三), the relativity of "the sun at noon" and "the thing born" is dialectically affirmed by "the sun setting" and "the thing dying”.

Chinese relativism resonates well with Western postmodernism in that both are rejecting the notion of a foundational truth, absolute and a priori, and insisting on the relative aspect of a truth, subject to human experience. We can feel the relativistic overtone right from the beginning of Dao De Jing which reads, "The Tao that can be told is not the eternal Tao. The name that can be named is not the eternal name"6 (Tao-Te Ching, ch.1). Laozi is apparently saying that humans cannot talk about the absolute. Or, as I understand it, the Dao as perceived by humans or phrased in human language is no longer the eternal. The absolute thus turns into the relative in the very end. Here, Laozi recognizes, it would seem, two kinds of human limitations: One is that of human subjectivity in perceiving the absolute; the other is that of human language in describing the eternal. While Laozi acknowledges the absolute (i.e., the Dao), he also understands it to be something "nameless", beyond language representation, as seen in the next line: "The nameless is the beginning of heaven and earth." Thus, the opposite of the nameless, the "named" or human language representation, has to be relative despite being recognized as "the mother of ten thousand things".

The notion of ming-shi (name and actuality), discussed in the previous section, also sheds light on the relativistic bent of classical Chinese thought for two obvious reasons. One is that Chinese ming-shi theories do not presuppose actualities as "universals", independent of naming (Makeham, p. 9). The other is that the correlation between ming and shi is indeed a dialectical unity of opposites: One exists exactly because of the other. Names and actualities, points out Makeham, "function as two parts of a whole where each partner relies on the other to such an extent that, without names, actualities would not become manifest, and without actualities, there would be nothing to be manifested as names” (p. 145). Thus, actuality or reality, as represented through the medium of language, is ultimately a relative entity to the Chinese mind.

Ming and shi can be translated into signifier and signified in Western terms. Derrida's deconstruction theory posits that there is no such thing as a metaphysical "presence" (similar to Chinese "object" or "actuality") existing independently of language representation: The signified is always already embedded in the signifier, to the extent that "how we see the world depends on the language we inherit" (Berkson, p. 105). Readers may have seen a strikingly similar view held by Zhuangzi: "Things are so because they are called so. What makes them so? Making them so makes them so. What makes them not so? Making them not so makes them not so" (Chuang Tzu, p. 40). ${ }^{7}$ So, epistemologically, humans are trapped in the "prison-house" of language. The postmodernist distrust in language in conveying truth and reality is also registered in Zhuangzi, who calls it "the guest of actuality" ${ }^{\prime 8}$ in the sense that ming is relative to shi. Due to the spatial limits, I will not elaborate further on the deconstructive "spirit” of Zhuangzi, but I would like to point out that Zhuangzi's relativism also carries a strong “dose” of perspectivism as seen in the following excerpt from his QiwuLun (齐 物论):

\footnotetext{
${ }^{6}$ In Chinese: 道可道, 非常道. 名可名, 非常名. 无名天地之始, 有名万物之母.

7 In Chinese: “物谓之而然. 恶乎然? 然于然. 恶乎不然? 不然于不然” (庄子: 齐物论).

${ }^{8}$ In Chinese: “名者, 实之宾也” (庄子: 逍遥游).
} 
Suppose I try saying something. What way do I have of knowing that if I say I know something I don't really not know it? Or what way do I have of knowing that if I say I don’t know something I don't really in fact know it? [...] Men claim that Mao-ch'iang and Lady Li were beautiful, but if fish saw them they would dive to the bottom of the stream, if birds saw them they would fly away, and if deer saw them they would break into a run. Of these four, which knows how to fix the standard of beauty for the world? The way I see it, the rules of benevolence and righteousness and the paths of right and wrong are all hopelessly snarled and jumbled. How could I know anything about such discriminations? (Chuang Tzu, pp. 45-46) ${ }^{9}$

Similar statements are many in the Zhuangzi. For example, in Tianxia (天下篇), Zhuangzi talks about the relative value of various skills and schools,

The world too often seizes upon one of its aspects, examines it, and pronounces it good. But it is like the case of the ear, the eye, the nose, and the mouth: each has its own kind of understanding, but their functions are not interchangeable. In the same way, the various skills of the hundred schools all have their strong points, and at times each may be of use. But none is wholly sufficient, none is universal. (Chuang Tzu, p. 364) ${ }^{10}$

So, for Zhuangzi, humans are trapped not only in the prison house of language but also in their own individual perspective, narrow and provincial, like a frog trapped in a well hence unable to comprehend the ocean.

As mentioned earlier, the ancient Chinese were pragmatic. Rather than looking for the absolute or universal, they were more interested in xing (行; doing), in dealing with the "ten thousand things" (wanwu; 万 物) or the particulars of an ever-changing world. Their philosophy is "primarily oriented towards 'this-world'," to quote Soo (1981, p. 78). I think it is important to keep this notion of pragmatism in mind when discussing relativism in early Chinese philosophy, for, while it poses epistemological challenges to metaphysics, it does not necessarily lead one into inaction, which is characteristically associated with the so-called "consistent" relativism. The latter, point out Hall and Ames, claims that "nothing practically follows [...] relativism but inaction," because there is "no satisfactory means" of getting to know things as they are (pp. 70-71). However, continue Hall and Ames, "if one tacitly or explicitly commits to one of a number of ways of acting, relativism has been practically abandoned" (p. 71). In that regard, Chinese relativism then can also be dubbed "non-relativist" because of its non-commitment to inaction. ${ }^{11}$ According to the authors, in Western philosophy, the issue of relativism is "mainly a red herring", for "most individuals who espouse relativism at the level of theory, abandon it when practical commitment is called for" (ibid.). I think this is especially true with many of the postmodernists, who would go out of their way to advocate a philosophy of praxis while at the same time arguing against philosophical premises on which one's action can be ultimately legitimized.

So far, in this section, I have discussed, rather briefly, three important concepts that can be found in common between postmodernism and classical Chinese philosophy, namely, those of change, dialectic, and relativism, which naturally forma triad, each in it being interconnected with, and implied by, the other. Apparently, what is presupposed in the triad is a non-recognition of the absolute or universal, something

\footnotetext{
${ }^{9}$ In Chinese: “尝试言之: 庸讵知吾所谓知之非不知邪? 庸讵知吾所谓不知之非知邪?......毛嫱丽姬, 人之所美也; 鱼见之 深入, 鸟见之高飞, 糜鹿见之决骤, 四者孰知天下之正色哉? 自我观之, 仁义之端, 是非之涂, 㚞然淆乱, 吾恶能知其 辩!”

${ }^{10}$ In Chinese: “天下多得一察焉以自好. 譬如耳目鼻口, 皆有所明, 不能相通. 犹百家众技也, 皆有所长, 时有所用. 虽然, 不该不遍, 一曲之师也.”

11 Some might cite wu-wei (无为, literally translated as “doing nothing”) as a counter-argument. However, I feel wu-wei is not necessarily about inaction but rather about doing things in a natural way.
} 
characteristic of modernist philosophy in its attempt to seek an all-inclusive metanarrative to describe and explain the world. Of course, there are many more concepts in Chinese philosophy just as there are many more in postmodernism. I chose to discuss these three partly because of space concerns for this paper. But I hope the discussion will suffice, and the reader will be able to see conceptual affinities (at least some) between classical Chinese philosophy and its postmodern counterpart in the West.

\section{Conclusion}

This paper is by no means conclusive, and I have no intention to make claims to finality. Rather, my purpose is to initiate a further discussion about possible connections between postmodernism and classical Chinese philosophy, something I feel is worthy of further debates among scholars both of Chinese and Western heritages. I do not wish to say that the two are a complete match for one another. Obviously, the movement of Western postmodernism has to be appreciated, first and foremost, within the historic and cultural context of the West, just as the development of Chinese philosophy must be studied based on an understanding of its own contextual constraints. Thus, to claim them as ideologically identical would be out of the question. However, as I argued in the beginning, it is quite possible that thinkers of different cultures and geographical regions, and of different historical periods, can come up with similar philosophical conclusions when addressing what is commonly known as the "human condition". In this light, the paper can be seen as an attempt to prove that possibility.

\section{References}

Berkson, M. (1996). Language: The guest of reality_Zhuangzi and Derrida on language, reality, and skillfulness. In Kjellberg and Ivanhoe (Eds.), Essays on skepticism, relativism, and ethics in the Zhuangzi (pp. 97-126). Albany, NY: State University of New York Press.

Bizzell, P., \& Herzberg, B. (1990). The rhetorical traditio: Readings from classical times to the present. Boston, MA: Bedford.

Derrida, J. (1976). Of grammatology (G. Spivak, Trans.). Baltimore: The Johns Hopkins University Press.

Foucault, M. (1972). The Archaeology of knowledge and the discourse on language (A. M. S. Smith, Trans.). New York: Barns \& Noble.

Foucault, M. (1990). The order of discourse (I. McLeod, Trans.). In P. Bizzell and B. Herzberg (Eds.), The rhetorical tradition: Readings from classical times to the present (pp. 1154-1164). Boston: Bedford.

Foucault, M. (1995). Discipline and punish: The birth of the prison (A. Sheridan, Trans.). (2nd ed.). New York: Vintage Books.

Gier, N. F. (2000). Spiritual Titanism: Indian, Chinese, and Western perspectives. Albany, NY: State University of New York Press.

Graham, A. C. (1989). Disputers of the Tao: Philosophical argument in ancient China. Chicago: Open Court.

Graham, A. C. (1992). Unreason within reason: Essays on the outskirts of rationality. LaSalle, Illinois: Open Court.

Hall, D., \& Ames, R. (1998). Thinking from the Han: Self, truth, and transcendence in Chinese and Western culture. Albany, NY: State University of New York Press.

Hansen, C. (1983). Language and logic in ancient China. Ann Arbor, Michigan: University of Michigan Press.

Hicks, S. (2004). Explaining postmodernism: Skepticism and socialism from Rousseau to Foucault. Tempe, Arizona: Scholargy Publishing.

Lao Tsu [Zi]. (1972). Tao-teching (G. F. Feng \& J. English, Trans.). Hampshire, England: Wildwood House.

Lenk, H. (1993). Introduction: If Aristotle had spoken and Wittgenstein known Chinese. In H. Lenk and G Paul (Eds.), Epistemological issues in classical Chinese philosophy (pp. 1-10). Albany, NY: State University of New York Press.

Loy, D. (1996). Zhuangzi and Nagarjuna on the truth of no truth. In Kjellberg and Ivanhoe (Eds.), Essays on skepticism, relativism, and ethics in the Zhuangzi (pp. 50-67). Albany, NY: State University of New York Press.

Makeham, J. (1994). Name and actuality in early Chinese thought. Albany, NY: State University of New York Press.

Postmodernism. (2013). In Encyclopcedia Britannica. Retrieved November 19, 2015, from 
http://www.britannica.com/topic/postmodernism-philosophy

Schwartz, B. I. (1989). The world of thought in ancient China. Cambridge, MA: Harvard University Press.

Seidman, S. (1994). Contested knowledge: Social theory in the postmodern era. Cambridge, MA: Blackwell Publishers.

Soo, F. (1981). Mao Tse-tung's theory of dialectic. Dordrecht, Holland: D. Reidel Publishing.

Wang, H. (2008, November 25). Fredric R. Jameson in China (Video file). Speech presented at Holberg Prize Symposium 2008:

$\begin{array}{llllll}\text { Fredric R. Jameson. } & \text { Retrieved } & \text { November } & \text { 12, 2013, }\end{array}$

http://www.holbergprisen.no/fredric-r-jameson/holbergprisens-symposium-2008.html

Zhuangzi. (1968). The complete works of Chuang Tzu (B. Watson, Trans.). New York: Columbia University Press. 